\title{
Antifeedant, horizontal transfer and repellent activities of free and microencapsulated food grade antioxidants against postharvest pest insects (Oryzaephilus surinamensis (LINNAEUS, 1758) and Tribolium castaneum (HERBST, 1797)) (Coleoptera: Silvanidae, Tenebrionidae) of peanuts (Arachis hypogaea L.) (Fabaceae)
}

\author{
DAiAnA GARCIA ${ }^{1 *}$, ANDREA Nesci ${ }^{1}$, NATAlia S. GiRARDi ${ }^{2}$, \\ M. ALEJANDRA PASSONE ${ }^{1}$, MIRIAM ETCHEVERRY ${ }^{1}$
}

Microbial Ecology Laboratory, Department of Microbiology and Immunology, Faculty of Exact Physical Chemistry and Natural Sciences, National University of Río Cuarto, Ruta 36 Km 601 (X5806JRA), Río Cuarto, Córdoba, Argentina

${ }^{1}$ Research Career, National Scientific and Technical Research Council

(CONICET), Argentina

${ }^{2}$ Posdoctoral fellow of National Scientific and Technical Research Council (CONICET)

\begin{abstract}
The aims of this work were to evaluate antifeedant, horizontal transfer and repellent activities of butylated hydroxyanisole (BHA) and butylated hydroxytoluene (BHT), free and microencapsulated, at different doses against Oryzaephilus surinamensis and Tribolium castaneum on peanut kernels. In general, negative values for the percentage feeding deterrence index (FDI) were found for Oryzaephilus surinamensis in the presence of these chemical treatments, suggesting a phagostimulant activity. In addition, untreated individuals died within 20 days of coming into contact with insects previously exposed to both antioxidants (BHA and BHT) and formulations (FBHA and F-BHT), regardless of the dose, while the insects in the controls died after this time. Since this work revealed evidence for the transfer of both free and microencapsulated antioxidants from treated to untreated individuals, we can confirm that horizontal transfer of these compounds takes place between treated and untreated insects. The evaluated compounds showed no repellent activity against $O$. surinamensis, which continued unaffected with its life cycle on both treated and untreated peanuts. On the other hand, Tribolium castaneum exhibited high FDI values, especially for the formulations, with mean values of 0.68 and 0.91 for F-BHA and F-BHT, respectively. No horizontal transfer was observed for this insect, but repellency was higher than $80 \%$ for free and encapsulated BHT. We can conclude that the mechanism of insecticidal action of antioxidants and their formulations was dependent on the type of insect evaluated. The insecticidal effect on
\end{abstract}

*Corresponding author: dgarcia@exa.unrc.edu.ar 
Oryzaephilus surinamensis could have been due to the direct intake of the chemical compounds added, whereas the negative effect on Tribolium castaneum could have been caused by starvation.

KEY WORDS: Oryzaephilus surinamensis, Tribolium castaneum, peanut, BHA, BHT, microcapsules, insecticide, antioxidants.

\section{INTRODUCTION}

Peanuts (Arachis hypogaea L.) are a very important dried fruit and are among the most widely used nuts because of their nutritional and taste properties. Some studies have revealed high levels of proteins and minerals, and also well-balanced fatty acid and antioxidant profiles in both nuts and oil (ÖZCAN et al. 2010, AKHTAR et al. 2014). Argentine peanut production is intended mainly for industrial use and export; in the latter case, quantities sent abroad have fluctuated between 0.44 and 0.68 million tons since 2012 (SIIA 2018). In view of the economic importance of peanuts, quality and safety are essential for commercialization. However, in many parts of the world, stored food commodities are susceptible to bio-deterioration by fungal and insect attack (GoULD 1995, ANONYMUS 2010, PRAKASH et al. 2012, KeDIA et al. 2014). Stored products of agricultural origin are attacked by more than 600 species of beetles, 70 species of moths and about 355 species of mites, causing quantitative and qualitative losses (RAJENDRAN 2002).

Oryzaephilus surinamensis (LinNAEUs, 1758) (Coleoptera; Silvanidae) and Tribolium castaneum (HERBST, 1797) (Coleoptera; Tenebrionidae) are two important species of insect pests which attack already infested or malformed grains, preferably stored cereal products and oleaginous seeds (HOWE 1965, SILVA \& LAPENTA 2011, TUCKER et al. 2014). Control of these types of insects is considered of great importance as they not only lead to deterioration of the raw material for direct consumption, but also act as spore vectors of mycotoxin-producing fungi (GARCIA et al. 2017). Generally, the use of synthetic insecticides is the main strategy employed to control pest insects (DABORN et al. 2007). However, the use of new alternatives to replace these products is of great importance if we wish to avoid their toxic effects on consumers and the generation of resistance in organisms. One such possibility is the addition of food-grade antioxidants like butylated hydroxyanisole (BHA) and butylated hydroxytoluene (BHT) (phenolic antioxidants), both free and encapsulated, which have elicited insecticidal effects on stored peanuts in previous studies (NESCI et al. 2011, GARCIA et al. 2016, 2017). The authors of those studies reported that the range from 20 to $30 \mathrm{mM}$ could be regarded as effective insecticide concentrations for both free and encapsulated antioxidants. Another recent study showed that free and microencapsulated BHA and BHT significantly decreased the weight and total protein 
content in both insects evaluated (GARCIA et al. 2017). In this last work, microencapsulation technology was applied with the aim of protecting food-grade antioxidants from the action of the physicochemical agents. It is clear that antioxidants applied in free or encapsulated forms have negative effects on Oryzaephilus surinamensis and Tribolium castaneum. Therefore, the study of the harmful effects of these compounds on both insect species needs to be continued in order to elicit their mode(s) of action. Accordingly, i) antifeedant activity ii) horizontal transfer and iii) repellent potential were evaluated in Oryzaephilus surinamensis and Tribolium castaneum treated with free and microencapsulated BHA and BHT.

\section{MATERIALS AND METHODS}

\section{Substrate and insects}

Peanuts collected during the harvest season 2015-2016 from Córdoba, Argentina, with an initial water content of $0.67 \mathrm{a}_{\mathrm{w}}$, were used throughout this study. Grains were sterilized in an autoclave at $120^{\circ} \mathrm{C}$ for 20 min and water activity $\left(a_{w}\right)$ was checked with an AquaLab Water Activity Meter 4TE (Decagon Devices, Inc.) with an accuracy of \pm 0.001 . Sawtoothed grain beetles Oryzaephilus surinamensis and red flour beetles Tribolium castaneum were obtained from the Laboratory of Agricultural Zoology, Faculty of Agronomy, University of Buenos Aires, Argentina. Mixed-sex adults of each insect aged 1-3 weeks' old were used in the assays. The insects were reared on a diet of wheat flour, corn starch and yeast (10:10:1.5) in plastic containers containing $200 \mathrm{~g}$ of this mixture at $27 \pm 1{ }^{\circ} \mathrm{C}$ and $70 \pm 5 \%$ relative humidity $(\mathrm{RH})$.

\section{Preparation of the antioxidant formulations}

Industrial grade antioxidants, i.e. 2(3)-tert-butyl-4 hydroxyanisole (BHA) and 2,6di(tert-butyl)-p-cresol (BHT), obtained from the Eastman Chemical Company (Kingsport, Tennessee, USA), were used as the core material. BHA had a purity of $98.5 \%$; it contained sulphated ash $100 \mu \mathrm{g} / \mathrm{g}$, citric acid $2.5 \mu \mathrm{g} / \mathrm{g}$, arsenic $3 \mu \mathrm{g} / \mathrm{g}$ and heavy metals $10 \mu \mathrm{g} / \mathrm{g}$ as contaminants, while BHT was $99 \%$ pure, containing only ash $100 \mu \mathrm{g} / \mathrm{g}$, arsenic $3 \mu \mathrm{g} / \mathrm{g}$ and heavy metals $10 \mu \mathrm{g} / \mathrm{g}$ as contaminants. The contaminants of these industrial grade antioxidants did not exceed the levels permitted by JECFA (1996). Gelatin (type A, gel strength 240 bloom) and gum arabic were used as the wall material. All the other chemicals used in these experiments were of analytical grade. The microcapsules were made by complex coacervation following the methodology proposed by GIRARDI et al. (2015). The microcapsules obtained were frozen at $-80^{\circ} \mathrm{C}$ for 3 hours and freeze-dried (L-T8-A-B3-CT, RIFICOR) under the following conditions: pressure $<0.05 \mathrm{mbar}$, cooling temperature -45 
${ }^{\circ} \mathrm{C}$, treatment time $72 \mathrm{~h}$. Empty capsules were treated using the same methodology but without the addition of BHA or BHT, in order to be used as controls by replacing the core material with peanut oil.

\section{Antifeedant activity evaluation}

To assess antifeedant activity, damaged grains (\%DG), their weight loss (\%WL) and feeding deterrence index (FDI) were determined for both insect species treated with free antioxidants (BHA and BHT) and their formulations (F-BHA and F-BHT). A microcosm assay was carried out by distributing sterile peanut grains $(50 \mathrm{~g})$ into $300 \mathrm{~mL}$ plastic jars. Three different doses of antioxidants and microcapsules were added separately: 10, 20 and $30 \mathrm{mM}$ for Oryzaephilus surinamensis and 15, 30, $45 \mathrm{mM}$ for Tribolium castaneum. The doses were chosen in accordance with GARCIA et al. (2017). Fifteen adults of each species were introduced into a jar and incubated in a chamber under controlled conditions $(25 \pm 1$ ${ }^{\circ} \mathrm{C}, 70 \pm 5 \%$ r.h.) for 90 days. Peanuts with empty capsules (without BHA or BHT) and without any compounds were used as controls. After the incubation time had elapsed, \%DG was assessed by observing emergence holes on the surface of the grains. Weight loss in treated and control peanut samples was calculated on a fresh weight basis using WL $=(\mathrm{WI}-$ $\mathrm{W}) / \mathrm{WI} \times 100$, where $\mathrm{WI}$ is the weight of the peanut sample before the experiment and $\mathrm{W}$ is the weight of the grains at the end of the study. Finally, the antifeedant action was determined according to the method of IsMAM et al. (1990): FDI $=(\mathrm{C}-\mathrm{T}) / \mathrm{C}$, where $\mathrm{C}$ is the weight loss of the control grains, and $\mathrm{T}$ is the weight loss of the treated peanuts. The assay was performed using three replicates per treatment. If the value of this index is unity, i.e. FDI $=1.00$, this corresponds to complete inhibition of feeding; half the effect is given by a value of 0.50 and no effect by zero FDI. Negative values indicate $(<0)$ feeding stimuli.

\section{Horizontal transfer evaluation}

For determining the horizontal transfer of food grade antioxidants, 15 adult insects were exposed to different doses of free and encapsulated BHA and BHT in order to obtain dead individuals: 10, 20 and $30 \mathrm{mM}$ for Oryzaephilus surinamensis and 15, 30, $45 \mathrm{mM}$ for Tribolium castaneum. The insects killed by the treatments were placed individually in vials with $1 \mathrm{~g}$ of food (milled peanuts) together with an unexposed live individual of the same species. The live insects were observed daily for approximately 60 days (or until all the insects in the experiment had died) to assess their mortality by contact with treated individuals. The extent of horizontal transfer was evaluated according to the survival time of untreated insects (the number of days that untreated insects remained alive). Insects killed by cold were used as controls. Fifteen replicates of each treatment for each insect species were assessed. All the treatments were compared with the controls to establish the extent of horizontal transfer of the compounds evaluated. 


\section{Evaluation of repellent activity}

The insect repellence test was carried out using lethal doses 50 (LD50) according to the results obtained by GARCIA et al. (2017). For Oryzaephilus surinamensis 5, 3, 11 and 17 $\mathrm{mM}$ of BHA, BHT, F-BHA and F-BHT, respectively, were used. Since high doses of BHA $(29 \mathrm{mM})$ and F-BHA $(65 \mathrm{mM})$ are needed to achieve the $\mathrm{LD}_{50}$ for Tribolium castaneum (GARCIA et al. 2017), this antioxidant was not evaluated. Thus, $11 \mathrm{mM}$ of BHT and $29 \mathrm{mM}$ of F-BHT were used for the latter species. Half the bottom of a Petri dish (14 cm diameter) was filled with treated peanut grains, while the other half was covered with untreated peanuts. Ten mixed-sex adults of each insect species were released at the centre of the Petri dishes. The plates were then covered and maintained in constant darkness under controlled conditions $\left(25 \pm 1{ }^{\circ} \mathrm{C}, 70 \pm 5 \% \mathrm{RH}\right)$. The number of Oryzaephilus surinamensis or Tribolium castaneum present on the treated and untreated portions of the experimental plates were recorded after 1, 5 and 8 days of exposure. The percentage of repellency (PR) was calculated as follows: $\mathrm{PR}=[(\mathrm{Nc}-\mathrm{Nt} / \mathrm{Nc}+\mathrm{Nt})] \times 100$, where $\mathrm{Nc}$ was the number of insects on the untreated grains and $\mathrm{Nt}$ was the number of individuals on the treated peanuts. Four replicates were used for each treatment, and the entire experiment was performed twice.

\section{Data Analysis}

All the variables determined in each assay of this study (\%DG, \%WL, horizontal transfer, FDI and PR) were analysed using ANOVA. Fisher's least significant difference (LSD) test at $\mathrm{p}<0.05$ was performed to establish statistical differences among mean values of controls and treatments for each variable assayed. Statistical analyses were carried out with Statgraphics ${ }^{\circledR}$ Centurion version XVI.I (Manugistics, Inc, Maryland, USA).

\section{RESULTS}

\section{Antifeedant activity \\ Oryzaephilus surinamensis: damage to peanut grains (\%DG)}

The effects of single factors as well as the two-way interactions of \%DG for different treatments (BHA, BHT, F-BHA, F-BHT) and doses $(10,20$ and $30 \mathrm{mM})$ were determined by ANOVA $(p<0.05)$. This parameter was significantly affected by chemical treatments $(\mathrm{DF}=3 ; F=17.71)$ followed by the doses $(\mathrm{DF}=2 ; F=3.97)$. However, no significant effects of the treatments and dose interaction were observed $(p<0.05)$.

The results obtained for $\% \mathrm{DG}$ in peanut grains by $O$. surinamensis for the different treatments are summarized in Fig. 1. The levels of damage estimated from both controls, without capsules (CWC) and with empty capsules (CEC), were of the order of 70 and 55\%, 
respectively. All treatments showed a significant decrease in \%DG values $(p<0.05)$ compared with both controls. In the case of free antioxidants, both showed significant damage reductions $(p<0.05)$ compared with controls, especially in the treatment with BHT $10 \mathrm{mM}$, where the percentage of damage was estimated at $8 \%$. Moreover, significant differences were found among the doses applied. With respect to the microencapsulated antioxidants, damage was the least (between 25-38\%) in F-BHA treatments, compared to the result obtained for peanuts treated with F-BHT, which showed damage of around $40 \%$.

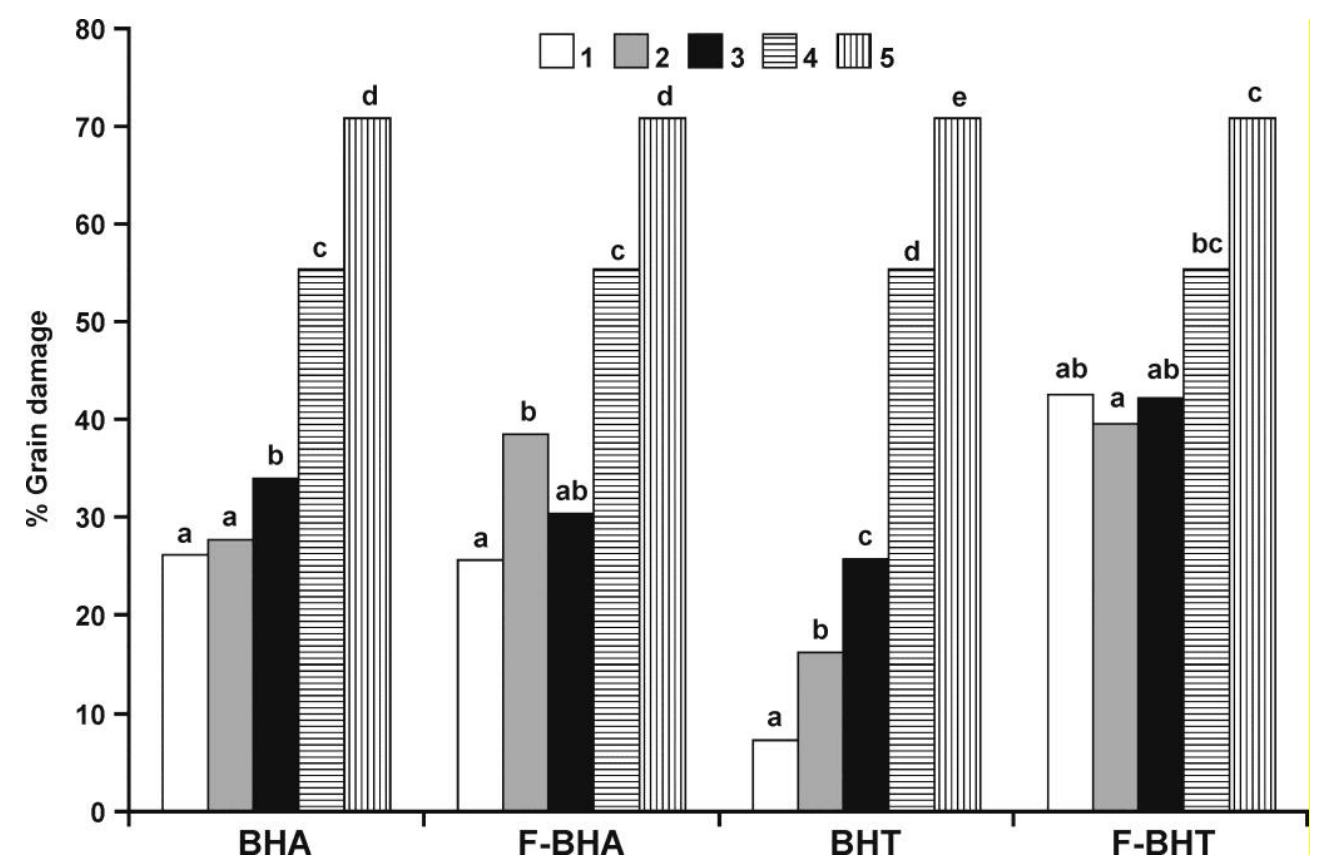

Fig. 1. Percentage of peanut kernel damage by Oryzaephilus surinamensis affected by treatment with different doses of BHA, F-BHA, BHT and F-BHT. 1 - $10 \mathrm{mM}$; 2 - $20 \mathrm{mM}$; 3 - $30 \mathrm{mM} ; 4$ - CEC; 5 - CWC. Bars with different letters for each treatment are significantly different according to the LSD test $(p<0.05)$.

Oryzaephilus surinamensis: Peanut weight loss $(\% W L)$ and feeding deterrence index (FDI)

ANOVA did not reveal any statistically significant differences $(p<0.05)$ when the impact of treatments and doses were estimated for both \%WL and FDI. Only F-BHA 30 $\mathrm{mM}$ (0.73), F-BHT $10 \mathrm{mM}(0.37)$ and F-BHT $30 \mathrm{mM}(0.18)$ showed positive values for FDI, but these indicate low levels of feeding inhibition (Table 1). 
Table 1. Percentage weight loss (\%WL) of peanut grains and feeding deterrence index (FDI) of $O$. surinamensis treated with different doses $(10,20$ and $30 \mathrm{mM})$ of BHA, BHT, F-BHA and F-BHT. Data with the same letter are not significantly different according to the LSD test $(p<0.05)$.

\begin{tabular}{|c|c|c|}
\hline \multirow[t]{2}{*}{ Treatment } & \multicolumn{2}{|c|}{ Feeding deterrence activity } \\
\hline & $\% \mathrm{WL}$ & FDI \\
\hline BHA 10 mM & $1.38 \pm 0.06 \mathbf{a}$ & $-0.24 \pm 0.05 \mathbf{a}$ \\
\hline BHA 20 mM & $1.37 \pm 0.20 \mathbf{a}$ & $-0.24 \pm 0.02 \mathbf{a}$ \\
\hline BHA 30 mM & $1.26 \pm 0.30 \mathbf{a}$ & $-0.13 \pm 0.30 \mathbf{a}$ \\
\hline F-BHA 10 mM & $1.27 \pm 0.26 \mathbf{a}$ & $-0.15 \pm 0.23 \mathbf{a}$ \\
\hline F-BHA $20 \mathrm{mM}$ & $1.12 \pm 0.41 \mathbf{a}$ & $0,00 \pm 0.35 \mathbf{a}$ \\
\hline F-BHA $30 \mathrm{mM}$ & $1.02 \pm 0.21 \mathbf{a}$ & $0.07 \pm 0.20 \mathbf{a}$ \\
\hline BHT 10 mM & $1.17 \pm 0.12 \mathbf{a}$ & $-0.06 \pm 0.10 \mathbf{a}$ \\
\hline BHT $20 \mathrm{mM}$ & $1.32 \pm 0.11 \mathbf{a}$ & $-0.20 \pm 0.10 \mathbf{a}$ \\
\hline BHT 30 mM & $1.14 \pm 0.16 \mathbf{a}$ & $-0.04 \pm 0.20 \mathbf{a}$ \\
\hline F-BHT 10 mM & $1.07 \pm 0.13 \mathbf{a}$ & $0.03 \pm 0.12 \mathbf{a}$ \\
\hline F-BHT 20 mM & $1.19 \pm 0.09 \mathbf{a}$ & $-0.07 \pm 0.07 \mathbf{a}$ \\
\hline F-BHT 30 mM & $0.91 \pm 0.25 \mathbf{a}$ & $0.20 \pm 0.23 \mathbf{a}$ \\
\hline CEC & $1.21 \pm 0.21 \mathbf{a}$ & $-0.08 \pm 0.18 \mathbf{a}$ \\
\hline CWC & $1.01 \pm 0.23 \mathbf{a}$ & - \\
\hline
\end{tabular}

\section{Tribolium castaneum: damage to peanut grains (\%DG)}

The effects of single factors as well as their two-way interactions on \%DG for both treatments (BHA, BHT, F-BHA, F-BHT) and doses (15, 30 and $45 \mathrm{mM})$ were determined by ANOVA $(\mathrm{p}<0.05)$. The percentage of damaged seeds was significantly affected by the doses $(\mathrm{DF}=2 ; \mathrm{F}=15.37)$, followed by the treatments $(\mathrm{DF}=3 ; \mathrm{F}=14.02)$ and their interactions $(\mathrm{DF}=6 ; \mathrm{F}=2.98)$

Fig. 2 shows the effect of BHA, BHT and their formulations on $\% \mathrm{DG}$ due to $T$. castaneum. Significant differences between treated grains and controls were found using the LSD test $(\mathrm{p}<0.05)$. Values estimated for the damage in both controls were 25 and $38 \%$ for CEC and CWC, respectively. For BHA and its formulation, the damage observed on peanut grains was 3 times lower at the highest doses assayed (30 and 45 mM for BHA; 45 $\mathrm{mM}$ for F-BHA) compared to the controls. Moreover, significant reductions $(\mathrm{p}<0.05)$ in $\%$ DG were found for BHT and F-BHT, where the values did not exceed $13 \%$ of damage, regardless of the doses. 


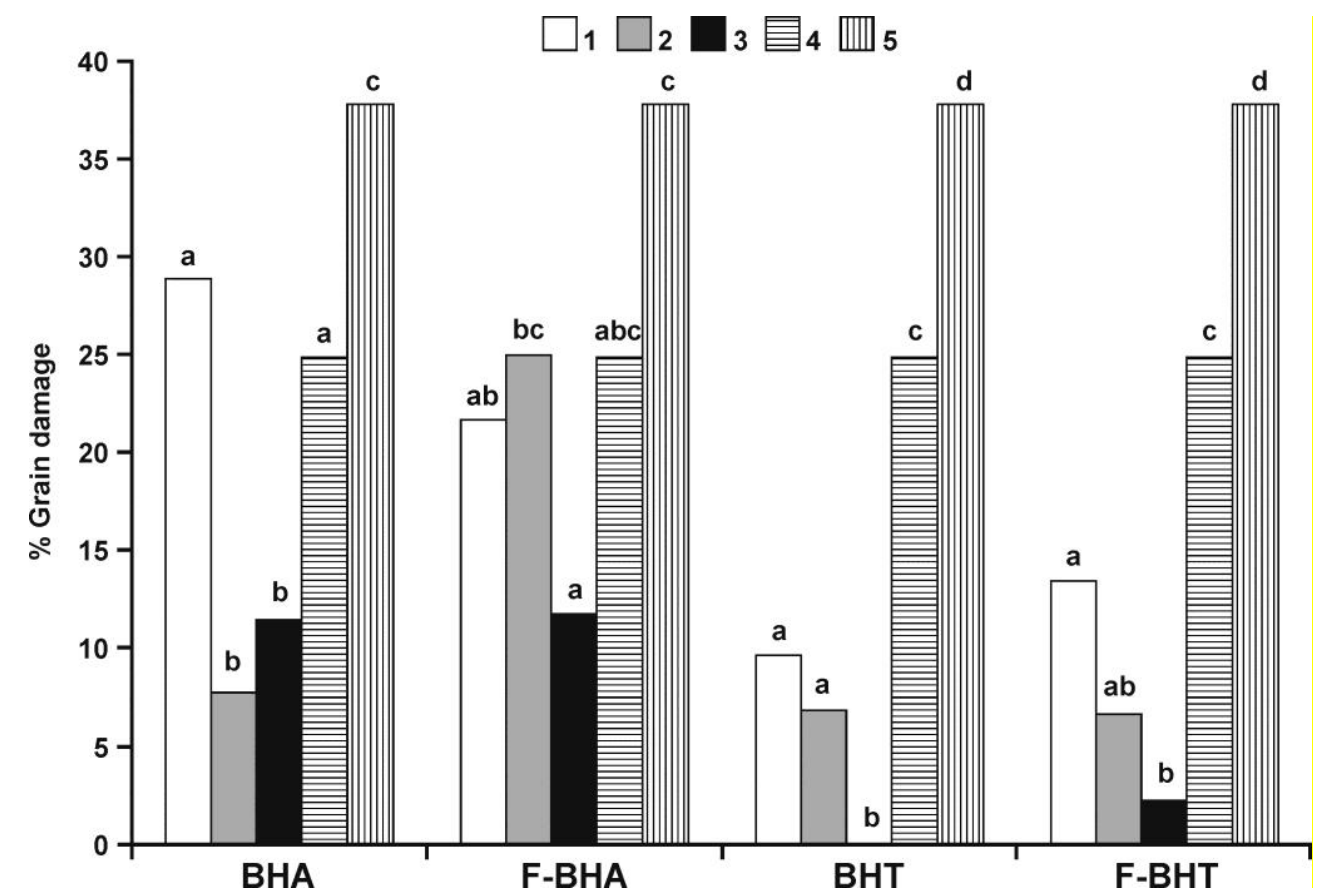

Fig. 2. Percentage of peanut kernel damage by $T$. castaneum affected by the treatment with different doses of BHA, F-BHA, BHT and F-BHT. $1-15 \mathrm{mM}$; $2-30 \mathrm{mM}$; $3-45 \mathrm{mM}$; 4 - CEC; 5 - CWC. Bars with different letters for each treatment are significantly different according to the LSD test $(p<0.05)$.

Tribolium castaneum: peanut weight loss (\%WL) and feeding deterrence index (FDI)

The effects of single factors as well as their two-way interactions for \%WL in both treatments (BHA, BHT, F-BHA, F-BHT) and doses $(15,30$ and $45 \mathrm{mM})$ were determined by ANOVA $(p<0.05)$. Values were significantly affected by treatments $(\mathrm{DF}=3 ; F=$ 161.15) and the interaction between treatment and dose ( $\mathrm{DF}=6 ; F=3.98)$. This parameter was not statistically affected by the concentration of pure or encapsulated antioxidants $(\mathrm{p}<0.05)(\mathrm{DF}=2 ; F=2.35)$.

According to ANOVA, FDI was also significantly affected by treatments $(p<0.05)$ (DF $=3 ; F=161.15)$, followed by the interaction between treatment and doses (DF $=6 ; F=$ 3.82). However, no significant differences were found for the different doses assayed ( $\mathrm{DF}=$ $2 ; F=1.95)$.

The values of $\% \mathrm{WL}$ and FDI obtained for $T$. castaneum with the different treatments are summarized in Table 2 . With respect to \%WL, CWC showed a high value (4.79\%), but the $\%$ observed for CEC was 1.24 times lower. The percentages recorded for both the free antioxidants and all doses (BHA and BHT, 15, 30 and $45 \mathrm{mM}$ ) were between the values 
recorded for the two controls (CWC and CEC). However, in the presence of microcapsules, the weight loss caused by $T$. castaneum was significantly reduced $(p<0.05)$. This parameter was 10 times lower in peanuts treated with microencapsulated BHT compared with the controls, regardless of the doses. Nevertheless, F-BHA showed percentages 3, 2 and 7 times lower for 15, 30 and $45 \mathrm{mM}$, respectively, compared with the controls. Moreover, both antioxidant foulations showed the highest FDI with a range of 0.50-0.85 and 0.84-0.98 for F-BHA and F-BHT, respectively, for the 3 doses assayed.

Table 2. Percentage weight loss (\%WL) of peanut grains and feeding deterrence index (FDI) of $T$. castaneum treated with different doses $(15,30$ and $45 \mathrm{mM})$ of BHA, BHT, F-BHA and F-BHT. Data with the same letter are not significantly different according to the LSD test $(p<0.05)$.

\begin{tabular}{|c|c|c|}
\hline \multirow[t]{2}{*}{ Treatment } & \multicolumn{2}{|c|}{ Feeding deterrence activity } \\
\hline & $\% \mathrm{WL}$ & FDI \\
\hline BHA 15 mM & $4.53 \pm 0.13 \mathbf{a b}$ & $0.05 \pm 0.03 \mathbf{a}$ \\
\hline BHA $30 \mathrm{mM}$ & $4.40 \pm 0.08 \mathbf{a b}$ & $0.08 \pm 0.02 \mathbf{a}$ \\
\hline BHA 45 mM & $4.24 \pm 0.09 \mathbf{a b}$ & $0.12 \pm 0.03 \mathbf{a b}$ \\
\hline F-BHA 15 mM & $1.70 \pm 0.81 \mathbf{c}$ & $0.70 \pm 0.20 \mathbf{d}$ \\
\hline F-BHA 30 mM & $2.60 \pm 0.82 \mathbf{d}$ & $0.50 \pm 0.15 \mathbf{c}$ \\
\hline F-BHA 45 mM & $0.67 \pm 0.71 \mathbf{e}$ & $0.90 \pm 0.15 \mathbf{e}$ \\
\hline BHT 15 mM & $4.37 \pm 0.07 \mathbf{a b}$ & $0.80 \pm 0.02 \mathbf{a}$ \\
\hline BHT 30 mM & $4.39 \pm 0.06 \mathbf{a b}$ & $0.80 \pm 0.12 \mathbf{a}$ \\
\hline BHT 45 mM & $4.64 \pm 0.47 \mathbf{a b}$ & $0.02 \pm 0.10 \mathbf{a}$ \\
\hline F-BHT 15 mM & $0.75 \pm 0.78 \mathbf{e}$ & $0.80 \pm 0.16$ de \\
\hline F-BHT $30 \mathrm{mM}$ & $0.09 \pm 0.05 \mathbf{e}$ & $1.00 \pm 0.01 \mathbf{e}$ \\
\hline F-BHT 45 mM & $0.41 \pm 0.21 \mathbf{e}$ & $0.90 \pm 0.04 \mathbf{e}$ \\
\hline CEC & $3.87 \pm 1.04 \mathbf{a}$ & $0.30 \pm 0.20 \mathbf{b}$ \\
\hline CWC & $4.79 \pm 0.05 \mathbf{b}$ & - \\
\hline
\end{tabular}

\section{Horizontal transfer of free and microencapsulated antioxidants}

Oryzaephilus surinamensis

ANOVA revealed statistical differences $(p<0.05)$ in survival time for the evaluated treatments $(\mathrm{DF}=13 ; F=4.1)$. The highest survival time for this insect species was found for CWC followed by F-BHT $30 \mathrm{mM}$ and CEC with 46.4, 21.6 and 19 days, respectively (Table 3). Values for this parameter were between 10.9 and 16.6 days for all treatments 
(except for F-BHT $30 \mathrm{mM}$ ), regardless of compound and dose, with significant reductions compared with the controls, according to the LSD test $(p<0.05)$.

Table 3. Mean survival (days) of $O$. surinamensis and Tribolium castaneum exposed to dead insects treated with different doses of BHA, F-BHA, BHT and F-BHT (10, 20 and 30 $\mathrm{mM}$ for Oryzaephilus surinamensis and 15, 30 and $45 \mathrm{mM}$ for Tribolium castaneum). Data with the same letter are not significantly different according to the LSD test $(p<0.05)$.

\begin{tabular}{|c|c|c|c|c|}
\hline Compound & Dose & O. surinamensis & Dose & T. castaneum \\
\hline & $10 \mathrm{mM}$ & $12.1 \pm 10.04 \mathbf{a}$ & $15 \mathrm{mM}$ & $30.67 \pm 21.88 \mathbf{a}$ \\
\hline \multirow[t]{3}{*}{ BHA } & $20 \mathrm{mM}$ & $16.6 \pm 23.39 \mathbf{a}$ & $30 \mathrm{mM}$ & $26.86 \pm 21.88 \mathbf{a}$ \\
\hline & $30 \mathrm{mM}$ & $14.4 \pm 13.45 \mathbf{a}$ & $45 \mathrm{mM}$ & $34.93 \pm 21.18 \mathbf{a}$ \\
\hline & $10 \mathrm{mM}$ & $11.8 \pm 7.98 \mathbf{a}$ & $15 \mathrm{mM}$ & $40.06 \pm 27.28 \mathbf{a}$ \\
\hline \multirow[t]{3}{*}{ F_BHA } & $20 \mathrm{mM}$ & $10.9 \pm 8.73 \mathbf{a}$ & $30 \mathrm{mM}$ & $38.07 \pm 23.89 \mathbf{a}$ \\
\hline & $30 \mathrm{mM}$ & $14.4 \pm 21.64 \mathbf{a}$ & $45 \mathrm{mM}$ & $37.47 \pm 24.16 \mathbf{a}$ \\
\hline & $10 \mathrm{mM}$ & $13.3 \pm 8.18 \mathbf{a}$ & $15 \mathrm{mM}$ & $38.74 \pm 29.52 \mathbf{a}$ \\
\hline \multirow[t]{3}{*}{ BHT } & $20 \mathrm{mM}$ & $13.5 \pm 8.57 \mathbf{a}$ & $30 \mathrm{mM}$ & $40.00 \pm 33.14 \mathbf{a}$ \\
\hline & $30 \mathrm{mM}$ & $14.3 \pm 9.33 \mathbf{a}$ & $45 \mathrm{mM}$ & $42.47 \pm 32.55 \mathbf{a}$ \\
\hline & $10 \mathrm{mM}$ & $15.7 \pm 8.96 \mathbf{a}$ & $15 \mathrm{mM}$ & $41.40 \pm 28.62 \mathbf{a}$ \\
\hline \multirow[t]{2}{*}{ F-BHT } & $20 \mathrm{mM}$ & $14.1 \pm 9.58 \mathbf{a}$ & $30 \mathrm{mM}$ & $62.27 \pm 27.88 \mathbf{b}$ \\
\hline & $30 \mathrm{mM}$ & $21.6 \pm 23.50 \mathbf{b}$ & $45 \mathrm{mM}$ & $42.07 \pm 31.77 \mathbf{a}$ \\
\hline CEC & - & $19.0 \pm 13.35 \mathbf{b}$ & - & $42.87 \pm 23.95 \mathbf{a b}$ \\
\hline CWC & - & $46.4 \pm 38.14 \mathbf{c}$ & - & $35.14 \pm 19.87 \mathbf{a}$ \\
\hline
\end{tabular}

\section{Tribolium castaneum}

Statistical analysis of the survival time of $T$. castaneum showed no significant differences according to ANOVA between the various treatments $(p<0.05)(\mathrm{DF}=13 ; F=$ 1.3). The survival time for individuals exposed to dead treated insects was between 27 and 62 days (Table 3). In general, no statistically significant differences were found between treatments and controls, except for F-BHT $30 \mathrm{mM}$, where the survival period was twice as high as in the controls.

\section{Repellent activity (PR) assay}

Table 4 shows the results obtained in the repellent activity assay for the two insect species, evaluated daily for 8 days. None of the treatments tested showed repellent activity on Oryzaephilus surinamensis. The highest PR observed was $28.9 \%$ for free BHA. Negative values (for F-BHA and CCV) mean that there was no repellency. However, a high 
value of PR was found for Tribolium castaneum (> 80\% for BHT and F-BHT) while CEC showed a percentage of $38 \%$.

Table 4. Average percentage repellent activity of Oryzaephilus surinamensis and Tribolium castaneum exposed to BHA, F-BHA, BHT and F-BHT. Data with the same letter are not significantly different according to the LSD test $(p<0.05)$.

\begin{tabular}{lcc}
\hline \multicolumn{1}{c}{ Species } & Treatment & Media \pm SD \\
\hline & BHA & $28.9 \pm 28.9 \mathbf{~ a}$ \\
O. surinamensis & F-BHA & $-6.7 \pm 21.5 \mathbf{~ b c}$ \\
& BHT & $0.0 \pm 28.3 \mathbf{~ b c}$ \\
& F-BHT & $6.7 \pm 24.6 \mathbf{~ a b}$ \\
& CEC & $-20.0 \pm 28.3 \mathbf{c}$ \\
& & \\
T. castaneum & BHT & $81.7 \pm 18.0 \mathbf{~ a}$ \\
& F-BHT & $86.7 \pm 19.7 \mathbf{~ a}$ \\
& CEC & $38.4 \pm 37.7 \mathbf{~ b}$ \\
\hline
\end{tabular}

\section{DISCUSSION}

Control of insect pests is of great importance owing to the economic losses they produce cause in stored grains. An alternative means of controlling them is the application of food grade antioxidants, in free or encapsulated form, as a replacement for synthetic insecticides. The idea of applying microencapsulation technology arose in order to protect antioxidants from the action of physicochemical, biological and technological agents. As the insecticidal effect of both antioxidants, free and in formulation, against Oryzaephilus surinamensis and Tribolium castaneum on peanut grains had already been evaluated in previous studies (NESCI et al. 2011, GARCIA et al. 2016, 2017), we aimed to discover the mode of action of these chemical compounds by studying antifeedant activity, horizontal transfer and repellent potency.

Firstly, differences in behaviour among insects were observed when their antifeedant activity was being evaluated. Oryzaephilus surinamensis showed a reduction of $\% \mathrm{DG}$ in the presence of all treatments (BHA, BHT, F-BHA and F-BHT) and doses (10, 20 and $30 \mathrm{mM}$ ) applied compared with the controls (CEC, CWC). The effect produced by BHA was maintained despite microencapsulation, whereas for BHT, \%DG was 3 times lower for the free antioxidant compared with the compound in formulation. With respect to \%WL, no significant differences were observed between controls and treatments, regardless of the doses. This means that this insect species continues to feed in the presence of these 
compounds and that mortality in the presence of these food grade antioxidants may be due to their intake. In general, negative values between -0.03 to -0.24 were recorded for FDI, suggesting that the treatments were phagostimulants. Thus, the insects fed more intensively on the treated peanut grains than in the control. Only F-BHA $30 \mathrm{mM}$, F-BHT 10 and 30 $\mathrm{mM}$, exhibited positive values but without exceeding 0.2 FDI. Some authors observed that phenolic antioxidants elicited phagostimulant effects against certain pests. DIAZ NAPAL \& PALACIOS (2015) evaluated the effects of two flavonoid antioxidants (pinocembrin and quercetin) on the feeding behaviour of Spodoptera frugiperda (J.E. SMITH, 1797) (Lepidoptera: Noctuidae). They found that at concentrations of $0.01-1 \mu \mathrm{g} / \mathrm{cm}^{2}$ each antioxidant functioned as a phagostimulant for this pest. These results are in accordance with BouAzIz et al. (2001), whose evaluation of the effect of the antioxidants tricin, tricin 7-O-glucoside and isoorientin showed them to act as phagostimulants on S. frugiperda. To the best of our knowledge, this is the first work to evaluate the antifeedant activity of Oryzaephilus surinamensis treated with these food grade antioxidants free and in formulation.

Secondly, the assay of antifeedant activity on Tribolium castaneum also showed a reduction in \%DG, this effect being well marked for BHT and F-BHT. Moreover, significantly lower values of $\% \mathrm{WL}$ were observed in peanuts treated with the two antioxidants compared with the controls, especially in formulations with reductions of $61 \%$ and $90 \%$ for F-BHA and F-BHT, respectively. These last results were similar to those obtained for FDI, in which the highest values observed were for F-BHA (0.5-0.9 FDI) and F-BHT (0.8-1 FDI) with total feeding inhibition achieved with a dose of $30 \mathrm{mM}$. In the light of these results, we can state that antioxidants, especially microencapsulated ones, act as antifeedant compounds for $T$. castaneum, possibly causing these insects to die of starvation. GARCIA et al. (2017) recorded a decrease in body weight for $T$. castaneum when this insect's population was exposed to these free antioxidants or their formulations. Thus, if insects do not feed, their body weight must fall. On the other hand, the antifeedant effect of BHT was previously demonstrated by SHTYKOVA et al. (2008), who obtained a nearly $100 \%$ antifeedant activity on applying Eudragit copolymer + BHT + surfactant formulations against the pine weevil (Hylobius abietis (LINNAEUS, 1758)). However, we were unable to find any papers assessing the antifeedant effects of antioxidants on this species. In general, this effect was evaluated by the use of essential oils or extracts from plant leaves or spices on different pest insects (HUANG \& Ho 1998, CHIAM et al. 1999, Tripathi et al. 2001, Du et al. 2011, Huang et al. 2013, TAGHizadeh \& MOHAMMADKHANI 2017, ZHANG et al. 2018).

Horizontal transfer of an insecticide occurs when an individual comes into contact with this chemical and transports it to another area, and then, through direct contact or some other means, transfers the insecticide to another individual who then suffers deleterious 
effects (BUCZKOWSKI \& SCHAL 2001, TUCKER et al. 2014). In our experiments, around 75$87 \%$ of untreated Oryzaephilus surinamensis died 20 days after being exposed to insects that had already died as a result of treatment with BHA and F-BHA, regardless of the doses. Also, BHT and F-BHT led to a high mortality (80\%) of insects exposed to individuals previously killed by these treatments. In the light of this high percentage mortality, we can confirm that pure and microencapsulated food grade antioxidants give rise to horizontal transfer between treated and untreated individuals of $O$. surinamensis. However, Tribolium castaneum did not display this horizontal transfer activity, because the live insects survived more than 50 days after having been placed in contact with dead treated insects. This last result was similar to those observed in both controls. The horizontal transfer of insecticides from a treated insect to some untreated ones has the advantage that these compounds can thereby be moved into inaccessible areas that are difficult to treat directly. This process has been demonstrated in a range of insect populations: cockroaches (LEPATOUREL 1999, BUCZKOWSKI \& SCHAL 2001, BUCZKOWSKI et al. 2001), mosquitoes (CHISM \& APPERSON 2003), ants (AUBUCHON et al. 2006) and other arthropods (TUCKER et al. 2014). In particular, TUCKER et al. (2014) demonstrated the horizontal transfer of methoprene in Tribolium castaneum and T. confusum JACQUELIN DU VAL, 1863.

Finally, as Oryzaephilus surinamens did not exhibit repellent activity in any of the treatments evaluated, these insects can develop in treated peanut kernels. In contrast, Tribolium castaneum showed marked repellent activity in the presence of BHT and F-BHT, with a percentage $>80 \%$ for the evaluated doses. For this species, BHA and its formulation were not evaluated owing to the high doses required to achieve $\mathrm{LD}_{50}(29$ and $65 \mathrm{mM}$, respectively) (GARCIA et al. 2017). Like antifeedant activity, much research has been carried out to evaluate repellent activity against pest insects using essential oils and plant extracts (KUTAS \& NÁDASY 2005, KUMAR et al. 2007, KHEMIRA et al. 2013, KediA et al. 2014). KHEMIRA et al. (2013), observed that $0.08 \mu 1 / \mathrm{m}^{2}$ of Eucalyptus astringens (MAIDEN) essential oil exhibited a repellent action against Oryzaephilus surinamensis $(55 \%)$ and Rhyzopertha dominica (FABRICIUS, 1792) (Coleoptera: Bostrichidae) $(58.75 \%)$ after $24 \mathrm{~h}$ of exposure. Moreover, the repellent activity of various essential oils (rosemary, lemon, basil, lime and peppermint) and their volatile components against Tribolium castaneum was determined by LEE et al. (2002). This effect could be to the high content of antioxidants present in essential oil or plant extracts (LEE et al. 2002, RADULOVIC et al. 2006, GARCIA et al. 2013).

To conclude, the presence of free or microencapsulated BHA and BHT does not prevent Oryzaephilus surinamensis from continuing to eat treated peanut grains. It is therefore the intake that could be responsible for killing these insects. This is the first report indicating that horizontal transfer occurred in this insect species with all the treatments evaluated. On 
the other hand, our results showed that Tribolium castaneum lost the desire to feed in the presence of both types of antioxidants, whether in the free state or in formulation. Repellence to these compounds was also demonstrated in this insect species. In general, the formulations maintained or increased the effect against both species. Finally, food grade antioxidants - free or in microcapsules - adversely affected the development of both species and could be an alternative to synthetic insecticides for controlling pest insects on stored grains. However, further large-scale evaluations, taking the conditions under which peanuts are stored into consideration, are required to corroborate this mode of action and the possible development of resistance mechanisms.

\section{ACKNOWLEDGEMENT}

The authors acknowledge UNRC/CONICET for the support from these programs. This work was carried out by grants from National Agency for Scientific and Technological Promotion (ANPCYT), FONCYT-PICT 1507/14, FONCYT-PICT 1654/15, and FONCYTPICT 1651/15.

\section{REFERENCES}

Akhtar S., Khalid N., Ahmed I., Shahzad A., Suleria H.A.R. 2014. Physicochemical Characteristics, Functional Properties, and Nutritional Benefits of Peanut Oil: A Review. Critical Reviews in Food Science and Nutrition, 54 (12): 1562-1575.

ANONYMUS 2010. What it will take to feed the world. Nature, 464: 969.

Aubuchon M.D., Mullen G.R., Eubanks M.D. 2006. Efficacy of broadcast and perimeter applications of s-methoprene bait on the red imported fire ant in grazed pastures. Journal of Economic Entomology, 99 (3): 621-625.

Bouaziz M., Simmonds M.S.J., Grayer R.J., Kite G.C., DAmaK M. 2001. Flavonoids from Hyparrhenia hirta STAPF (Poaceae) growing in Tunisia. Biochemical Systematics and Ecology, 29 (8): 849-851.

Buczkowski G., Kopanic JR. R.J., Schal C. 2001. Transfer of ingested insecticides among cockroaches: effects of active ingredient, bait formulation, and assay procedures. Journal of Economic Entomology, 94 (5): 1229-1236.

BUCZKOWSKI G., SCHAL C. 2001. Method of insecticide delivery affects horizontal transfer of fipronil in the German cockroach (Dictyoptera: Blattellidae). Journal of Economic Entomology, 94 (3): 680-685.

Chiam W.Y., Huang Y., CHEN S.X., Ho S.H. 1999. Toxic and Antifeedant Effects of Allyl Disulfide on Tribolium castaneum (Coleoptera: Tenebrionidae) and Sitophilus zeamais (Coleoptera: Curculionidae). Journal of Economic Entomology, 92 (1): 239-245. 
CHISM B.D., APPERSON C.S. 2003. Horizontal transfer of the insect growth regulator pyriproxyfen to larval microcosms by gravid Aedes albopictus and Ochlerota tustriseriatus mosquitoes in the laboratory. Medical and Veterinary Entomology, 17 (2): 211-220.

Daborn P.J., Lumb C., Boey A., Wong W., Ffrench-Constant R.H., Batterham P. 2007. Evaluating the insecticide resistance potential of eight Drosophila melanogaster cytochrome P450 genes by transgenic over-expression. Insect Biochemistry and Molecular Biology, 37 (5): $512-519$.

Diaz Napal G.N., Palacios S.M. 2015. Bioinsecticidal effect of the flavonoids pinocembrin and quercetin against Spodoptera frugiperda. Journal of Pest Science, 88 (3): 629-635.

Du S.S., Wang C.F., Li J., Zhang H.M., Liu Q.Z., Liu Z.L., Deng Z.W. 2011. Antifeedant Diterpenoids against Tribolium castaneum from the Stems and Twigs of Ceriops tagal (Rhizophoraceae). Molecules, 16 (7): 6060-6067.

Garcia D., Ramos A.J., SANChIS V., MARIN S. 2013. Equisetum arvense hydro-alcoholic extract: phenolic composition and antifungal and antimycotoxigenic effect against Aspergillus flavus and Fusarium verticillioides in stored maize. Journal of the Science of Food and Agriculture, 93 (9): $2248-2253$.

Garcia D., Girardi N., Passone M.A., Nesci A., Etcheverry M. 2016. Evaluation of food grade antioxidant formulation for sustained antifungal, antiaflatoxigenic and insecticidal activities on peanut conditioned at different water activities. Journal of Stored Products Research, 65: 6-12.

Garcia D., Girardi N., Passone M.A., Nesci A., Etcheverry M. 2017. Harmful Effects on Oryzaephilus surinamensis (L.) and Tribolium castaneum by Food Grade Antioxidants and their Formulations in Peanut Kernel. Journal of Food Chemistry and Nanotechnology, 3: 86-92.

Girardi N., Garcia D., Nesci A., Passone M.A., Etcheverry M. 2015. Stability of food grade antioxidants formulation to use as preservatives on stored peanut. LWT - Food Science and Technology, 62 (2): 1019-1026.

Gould G.W. 1995. Biodeterioration of Foods and an Overview of Preservation in the Food and Dairy Industries. International Biodeterioration \& Biodegradation, 36 (3-4): 267-277.

Howe R.W. 1965. A summary of estimates of optimal and minimal conditions for population increase of some stored products insects. Journal of Stored Products Research, 1 (2): 177-184.

HUANG Y., Ho S.H. 1998. Toxicity and antifeedant activities of ainnamaldehyde against the grain storage insects, Tribolium castaneum (HERBST) and Sitophilus zeamais MotsCH. Journal of Stored Products Research, 34 (1): 11-17.

Huang S.-H., Xian J.-D., Kong S.-Z., Li Y.-C., Xie J.-H., Lin J., Chen J.-N., Wang H.-F., Su Z.-R. 2013. Insecticidal activity of pogostone against Spodoptera litura and Spodoptera exigua (Lepidoptera: Noctuidae). Pest Management Science, 70 I3): 510-516.

ISMAM M.B., Koul O., LUEZYNSKI N. 1990. Insecticidal and antifeedant bioactivity of neem oil and their relationship to azadirachtin content. Journal of Agricultural and Food Chemistry, 38 (6): 1406-1411.

JECFA [Joint FAO/WHO Expert Committee on Food Additives] 1996. Toxicological evaluation of certain food additives and contaminants in food. WHO Food Additives Series, No 35. Joint FAO/WHO Expert Committee on Food Additives, Geneva. 
Kedia A., Prakash B., Mishra P.K., Chanotiya C.S., Dubey N.K. 2014. Antifungal, antiaflatoxigenic, and insecticidal efficacy of spearmint (Mentha spicata L.) essential oil. International Biodeterioration \& Biodegradation, 89: 29-36.

Khemira S., Mediouni-Ben JemâA J., Haouel S., Khouja M.L. 2013. Repellent activity of essential oil of Eucalyptus astringens against Rhyzopertha dominica and Oryzaephilus surinamensis. Acta Horticola, 997: 207-213.

Kumar R., Srivastava M., Dubey N.K. 2007. Evaluation of Cymbopogon martinii Oil Extract for Control of Postharvest Insect Deterioration in Cereals and Legumes. Journal of Food Protection, 70 (1): 172-178.

KUTAS J., NÁDASY M. 2005. Antifeedant effects of several plant extracts on Colorado potato beetle larvae. Acta Phytopathologica et Entomologica Hungarica, 40 (3): 355-365.

Lee B.-H., Lee S.-E., AnNis P.-C., Pratt S.J., Park B.-S., Tumaali F. 2002. Fumigant Toxicity of Essential Oils and Monoterpenes Against the Red Flour Beetle, Tribolium castaneum HeRBST. J. Asia-Pacific Entomology, 5 (2): 237--240.

LePatourel G. 1999. Secondary transfer of toxicity following consumption of fipronil gel bait by oriental cockroaches (Dictoptera: Blattidae). [in:] W.H RoBinson., F. ReTTICH, G.W. RAMBO (eds.). Proceedings of the Third International Conference on Urban Pests, 18-22 July 1999, Prague, Czech Republic, Grafické Závody, Prague, Czech Republic, 127-132.

Nesci A., Montemarani A., Passone M.A., Etcheverry M. 2011. Insecticidal activity of synthetic antioxidants, natural phytochemicals, and essential oils against an Aspergillus section Flavi vector (Oryzaephilus surinamensis L.) in microcosm. Journal of Pest Science, 84 (1): 107-115.

ÖZCAN M.M. 2010. Some nutritional characteristics of kernel and oil of peanut (Arachis hypogaea L.). Journal of Oleo Science, 59 (1): 1-5.

Prakash B., Singh P., Kedia K., Singh A., Dubey N.K. 2012. Efficacy of essential oil combination of Curcuma longa L. and Zingiber officinale Rosc. as a postharvest fungitoxicant, aflatoxin inhibitor and antioxidant agent. Journal of Food Safety, 32 (3): 279-288.

Rajendran S. 2002. Postharvest pest losses. [in:] D. Pimentel (ed.). Encyclopedia of Pest Management. Marcel Dekker, Inc., New York, 654-656.

Radulovic N., Stojanovic G., Palic R. 2006. Composition and antimicrobial activity of Equisetum arvense L. essential oil. Phytotherapy Research, 20 (1): 85-88.

SIIA [Sistema Integrado de Información Agropecuaria] 2018. Internet: http://www.siia.gov.ar/_apps/ siia/buscador/mostrar.php

Silva G.A.R., LAPENTA A.S. 2011. Genetic variability in esterases and the insecticide resistance in Brazilian strains of Oryzaephilus mercator and Oryzaephilus surinamensis (Coleoptera: Silvanidae). Bulletin of Entomology Research, 101 (2): 177-185.

Shtykova L., Masuda M., ERIKSSON SJödin K., Marling E., SChlyter F., NydÉn M. 2008. Latex coatings containing antifeedants: Formulation, characterization, and application for protection of conifer seedlings against pine weevil feeding. Progress in Organic Coatings, 63 (2): 160-166.

Taghizadeh R., Mohammadkhani N. 2017. Antifeedant activity of Descurainia sophia and Thuja orientalis extracts against Tribolium castaneum (Coleoptera: Tenebrionidae). Journal of Crop Protection, 6 (6): 487-495. 
Tripathi A.K., Prajapati V., Aggarwal K.K., Kumar S. 2001. Toxicity, feeding deterrence, and effect of activity of 1,8-cineole from Artemisia апnиa on progeny production of Tribolium castaneum (Coleoptera: Tenebrionidae). Journal of Economic Entomology, 94 (4): 979-983.

Tucker A.M., CAmpbell J.F., ARThuR F.H., Zhu K.Y. 2014. Horizontal transfer of methoprene by Tribolium castaneum (HERBST) and Tribolium confusum JACQUELIN DU VAL. Journal of Stored Products Research, 57: 73-79.

Zhang W., Wang Y., Geng Z., Guo S., Cao J., Zhang Z., Pang X., Chen Z., Du S., Deng Z. 2018. Antifeedant Activities of Lignans from Stem Bark of Zanthoxylum armatum DC. against Tribolium castaneum. Molecules, 23 (3): 617--627.

Received: 13 August 2018

Accepted: 18 December 2018 